\title{
Symptom Diversity of Patients with Reflux Esophagitis: Effect of Omeprazole Treatment
}

\author{
Kyoichi Adachi ${ }^{1 *}$, Yoshinobu Matsumori², Tomoo Fujisawa ${ }^{3}$, Tomoari Kamada ${ }^{4}$, \\ Masayasu Kusaka ${ }^{5}$, Tsuneyo Ohumi ${ }^{6}$, Ryuichi Iwakiri ${ }^{7}$, Kanako Yamaguchi', \\ Akiko Danjo $^{8}$, Kazutoshi Hori ${ }^{9}$, Toshihiko Tomita ${ }^{9}$, Takamasa Hayashi ${ }^{10}$, Ken Haruma ${ }^{4}$, \\ Kazuma Fujimoto ${ }^{7}$, Hiroto Miwa ${ }^{9}$, and Yoshikazu Kinoshita ${ }^{1}$ \\ ${ }^{1}$ Department of Gastroenterology and Hepatology, Shimane University School of Medicine, 89-1, Enya-cho, Izumo, \\ Shimane 693-0021, Japan \\ ${ }^{2}$ Takatsuki General Hospital, 1-3-13, Kosobe-cho, Takatsuki, Osaka 569-1115, Japan \\ ${ }^{3}$ Matsue Red Cross Hospital, 200, Horo-machi, Matsue, Shimane 690-0886, Japan \\ ${ }^{4}$ Division of Gastroenterology, Department of Internal Medicine, Kawasaki Medical School, 577, Matsushima, \\ Kurashiki, Okayama 701-0114, Japan \\ ${ }^{5}$ Kusaka Hospital, 1122, Nishi-katakami, Bizen, Okayama 705-0021, Japan \\ ${ }^{6}$ Ohumi Clinic, 934-1, Kawanabe, Tsuyama, Okayama 708-0842, Japan \\ ${ }^{7}$ Department of Internal Medicine and Gastrointestinal Endoscopy, Saga Medical School, 5-1-1, Nabeshima, Saga \\ 849-0937, Japan \\ ${ }^{8}$ Saga Social Insurance Hospital, 3-8-1, Hyogo-minami, Saga 849-0918, Japan \\ ${ }^{9}$ Department of Internal Medicine, Hyogo College of Medicine, 1-1, Mukogawa-cho, Nishinomiya, Hyogo 663-8131, \\ Japan \\ ${ }^{10}$ Amagasaki Central Hospital, 1-12-1, Shioe, Amagasaki, Hyogo 661-0976, Japan
}

Received 13 March, 2006; Accepted 29 March, 2006

\begin{abstract}
Summary Objective: A number of clinical trials have reported that proton-pump inhibitors are efficacious in the treatment of upper abdominal symptoms, but most of these trials have been carried out in Caucasians. This study investigated the type of upper abdominal symptoms reported by Japanese patients with reflux esophagitis and the efficacy of omeprazole for treating their symptoms.

Methods: A total of 234 patients aged $\geq 20$ years with grade $A$ to $D$ reflux esophagitis were enrolled in this multicenter, open study. Patients received omeprazole 10 or $20 \mathrm{mg} / \mathrm{day}$ for 4 weeks. Symptom and quality of life questionnaires were administered at baseline, week 2 and week 4.
\end{abstract}

Results: Among the 221 evaluable patients, almost 70\% reported reflux-type symptoms (e.g. regurgitation and heartburn). Ulcer- and dysmotility-type symptoms (e.g. stomach pain and belching) were also common, occurring in 38-62\% of patients. After 4 weeks of omeprazole

\footnotetext{
*To whom correspondence should be addressed.

Tel: $+81-853-20-2190 \quad$ Fax: $+81-853-20-2187$

E-mail: kadachi@med.shimane-u.ac.jp

Abbreviations: ARD, acid-related disease; FD, functional dyspepsia; GSRS, Gastrointestinal Symptoms Rating Scale; PPIs, proton pump inhibitors; PU, peptic ulcer; QOL,quality of life; RE, reflux esophagitis; SD, standard deviation.
} 


\begin{abstract}
treatment, all symptoms (except anorexia) were improved in approximately $90 \%$ of patients. Quality of life was also improved following omeprazole treatment.

Conclusion: Reflux-type symptoms as well as ulcer- and dysmotility-type symptoms were seen frequently in Japanese patients with reflux esophagitis. However, omeprazole improved all symptom types and quality of life in this patient population.
\end{abstract}

\title{
Key Words: Upper abdominal symptoms, reflux esophagitis, functional dyspepsia, omeprazole
}

\section{Introduction}

In Japan, a large number of patients experience upper abdominal symptoms such as heartburn, stomach discomfort and a sensation of fullness. In the majority of patients, symptoms are mild and can be controlled by over-the-counter drugs. The rest of the patients visiting hospitals have severer symptoms and decreased quality of life (QOL) $[1,2]$, but their symptoms are not always treated satisfactorily. Patients usually have variety of symptoms and it sometimes makes physicians felt difficulty to select adequate treatment unless the symptoms are clearly accounted to organic disease, leaving patients in an undesirable condition.

The pathogenesis of upper abdominal symptoms where no evidence of organic disease is present remains unknown. In the meantime, the concept of functional dyspepsia (FD) has been established whereby patients with a number of upper abdominal symptoms are classified into three subtypes according to the dominant symptoms for treatment purpose, but treatment outcomes are uncertain using this approach [3, 4] because the majority of symptoms overlap across the subtypes of FD [5, 6]. Upper abdominal symptoms are also seen in patients with acid-related disease (ARD) such as peptic ulcer (PU) and reflux esophagitis (RE). Symptoms in such patients are improved according to the treatment of $\mathrm{PU}$ or RE by antisecretory agents, suggesting that upper abdominal symptoms are somewhat associated with gastric acid.

Proton pomp inhibitors (PPIs) are widely used for treatment of ARD. PPIs show efficacy on the upper abdominal symptoms observed in those patients. PPIs also showed a certain efficacy on symptom control in patients with FD. Positive results of treatment with a PPI for Helicobacter pylori (H. pylori)-negative dyspepsia has recently been reported in Caucasians; Veldhuyzen van Zanten et al. reported that omeprazole was superior to ranitidine, cisapride and placebo [7]. However, it is uncertain whether the Japanese have a similar response because study of PPIs for treatment of upper abdominal symptoms in Japanese population is limited.

We considered it was useful to know the type of upper abdominal symptoms and the treatment effect of PPIs in Japanese patients in order to investigate whether PPIs are effective for the symptoms. The purpose of this study, therefore, was to confirm symptom variety in patients with $\mathrm{RE}$ and to investigate whether symptoms were controlled during 4-weeks treatment with omeprazole.

\section{Materials and Methods}

This was a multi-center, open study conducted at 79 centers in Japan from November 2005 to February 2006.

\section{Subjects}

Patients were eligible for the study if they were aged 20 years or older and had grade A to D reflux esophagitis (according to the Los Angeles Classification [8]) with one or more upper abdominal symptoms other than heartburn. Patients were excluded if they had been treated with a PPI and/or $\mathrm{H}_{2}$ receptor antagonists within 1 week prior to enrollment; had a prior history of gastrointestinal tract resections and/or vagotomy; had Zollinger-Ellison syndrome and/or pernicious anemia; and/or had complications of severe liver/kidney/heart disorders. Verbal informed consent was obtained from patients and the ethics committee for each site approved the protocol.

\section{Study design}

The schedule of the study is shown in Table 1. At study entry, patient eligibility was determined and an endoscopy was performed. The presence of gastrointestinal symptoms was assessed by a questionnaire, in which pathognomonic symptoms for both reflux-type and ulcer- and dysmotilitytype (Table 2) were listed. QOL was measured by patients with the Gastrointestinal Symptoms Rating Scale (GSRS), which is a validated QOL questionnaire designed for gastrointestinal symptoms $[9,10]$.

Table 1. Summary of items to be evaluated

\begin{tabular}{|c|c|c|c|}
\hline Parameter & $\begin{array}{c}\text { Week } 0 \\
\text { (study entry) }\end{array}$ & 2 weeks & 4 weeks \\
\hline Patient background, history & $\checkmark$ & & \\
\hline Endoscopy & $\checkmark$ & & \\
\hline Gastrointestinal symptoms & $\checkmark$ & $\checkmark$ & $\checkmark$ \\
\hline QoL (GSRS) & $\checkmark$ & $\checkmark$ & $\checkmark$ \\
\hline Drug dosage/compliance & & $\checkmark$ & $\checkmark$ \\
\hline
\end{tabular}

GSRS $=$ Gastrointestinal Symptoms Rating Scale. 
Table 2. Symptom types

\begin{tabular}{ll}
\hline Symptom type & \multicolumn{1}{c}{ Symptoms as listed in the questionnaire } \\
\hline $\begin{array}{l}\text { Reflux-type } \\
\text { symptoms }\end{array}$ & $\begin{array}{l}\text { Tickling or tingling in the throat } \\
\text { Feeling that sour contents are coming up } \\
\text { from the stomach (regurgitation) } \\
\text { Feeling that something is stuck in the throat } \\
\text { Burning sensation in the chest (heartburn) }\end{array}$ \\
& $\begin{array}{l}\text { Pain in the stomach } \\
\text { Ulcer- and }\end{array}$ \\
dysmotility-type & $\begin{array}{l}\text { Nausea or feeling sick } \\
\text { symptoms }\end{array}$ \\
& $\begin{array}{l}\text { Heavy feeling in the stomach } \\
\text { Feeling of fullness in the stomach } \\
\end{array}$ \\
& Belching \\
& No appetite (anorexia)
\end{tabular}

Patients received either omeprazole (AstraZeneca K.K., Osaka, Japan) $10 \mathrm{mg}$ once daily or $20 \mathrm{mg}$ once daily for four weeks. The dosage was decided at the physician's discretion based on the patient's condition. Change of dosage during the study was allowed and date of change of dosage was recorded. Concomitant use of other PPIs or $\mathrm{H}_{2}$ receptor antagonists during the study period was prohibited.

\section{Efficacy assessment}

Treatment response was assessed for the symptoms presented at study entry by a 4-point grade categorical scale $(1=$ complete relief; $2=$ better than before; $3=$ no change; $4=$ worse than before). In cases of withdrawal, evaluations were made at the point of withdrawal.

The primary efficacy variable was symptom improvement rate at week 4 (i.e. "complete relief" or "better than before"). Symptom improvement rate at week 2, complete symptom relief rate and GSRS score at weeks 2 and 4 were assessed subsequently. Symptom improvement rate and complete symptom relief rate in each dosage were also assessed.

\section{Statistical analysis}

Symptom improvement rate, complete symptom relief rate and GSRS scores were assessed descriptively. Symptom improvement rate was shown in two separate figures in accordance with the symptoms as summarized in Table 2; Reflux-type symptoms and ulcer- and dysmotility-type symptoms. For statistical analysis of GSRS scores, Student's t-tests were used. $\mathrm{P}<0.05$ was considered to be statistically significant.

\section{Results}

\section{Study population}

A total of 234 patients were entered in the study, of which 13 were excluded due to violation of inclusion or exclusion criteria. Of the remaining 221 patients, 58 received omeprazole $10 \mathrm{mg} /$ day and 158 received $20 \mathrm{mg} /$
Table 3. Baseline characteristics

\begin{tabular}{|c|c|c|c|}
\hline & & Patients (n) & $\%$ \\
\hline \multirow[t]{2}{*}{ Gender } & Male & 104 & 47.1 \\
\hline & Female & 117 & 52.9 \\
\hline \multirow[t]{6}{*}{ Age (years) } & $26-39$ & 25 & 11.3 \\
\hline & $40-59$ & 77 & 34.8 \\
\hline & $60-89$ & 119 & 53.8 \\
\hline & $<65$ & 127 & 57.5 \\
\hline & $\geq 65$ & 94 & 42.5 \\
\hline & Mean (SD) & $\begin{array}{l}59.1 \\
(13.6)\end{array}$ & Not applicable \\
\hline \multirow[t]{5}{*}{ Body mass index } & $<20$ & 24 & 10.9 \\
\hline & $21-24$ & 115 & 52 \\
\hline & $\geq 25$ & 65 & 29.4 \\
\hline & Mean (SD) & $\begin{array}{l}23.8 \\
(3.6)\end{array}$ & Not applicable \\
\hline & Unknown & 17 & 7.7 \\
\hline \multirow{4}{*}{$\begin{array}{l}\text { Smoking } \\
\text { (cigarettes/day) }\end{array}$} & Non-smoker & 172 & 77.8 \\
\hline & $<20$ & 20 & 9 \\
\hline & $\geq 20$ & 24 & 10.9 \\
\hline & Unknown & 5 & 2.3 \\
\hline \multirow[t]{4}{*}{ Alcohol } & None & 121 & 54.8 \\
\hline & Sometimes & 44 & 19.9 \\
\hline & Everyday & 53 & 24 \\
\hline & Unknown & 3 & 1.4 \\
\hline \multirow[t]{4}{*}{ RE grade } & A & 129 & 58.4 \\
\hline & B & 65 & 29.4 \\
\hline & $\mathrm{C}$ & 25 & 11.3 \\
\hline & $\mathrm{D}$ & 2 & 0.9 \\
\hline \multirow{4}{*}{$\begin{array}{l}\text { History of } \\
\text { RE (months) }\end{array}$} & $<1$ & 87 & 39.4 \\
\hline & 1 to $<6$ & 33 & 14.9 \\
\hline & $\geq 6$ & 45 & 20.4 \\
\hline & Unknown & 56 & 25.3 \\
\hline \multirow{5}{*}{$\begin{array}{l}\text { Other gastrointestinal } \\
\text { diseases }\end{array}$} & None & 107 & 48.4 \\
\hline & $\begin{array}{l}\text { Gastric } \\
\text { ulcer }\end{array}$ & 7 & 3.2 \\
\hline & $\begin{array}{l}\text { Duodenal } \\
\text { ulcer }\end{array}$ & 9 & 4.1 \\
\hline & $\begin{array}{l}\text { Atrophic } \\
\text { gastritis }\end{array}$ & 49 & 22.2 \\
\hline & Other & 53 & 24 \\
\hline \multirow{3}{*}{$\begin{array}{l}\text { Initial omeprazole } \\
\text { dosage (mg/day) }\end{array}$} & 10 & 58 & 26.2 \\
\hline & 20 & 158 & 71.5 \\
\hline & Other & 5 & 2.3 \\
\hline
\end{tabular}

$\mathrm{SD}=$ standard deviation .

day. Baseline characteristics for the 221 patients are presented in Table 3. Patients with a severe grade of RE were limited - only $12 \%$ had grade C or D RE. Atrophic gastritis was the most common gastrointestinal complication ( $22 \%$ of patients), whereas peptic ulcer occurred in less than $10 \%$ (Table 3 ). 


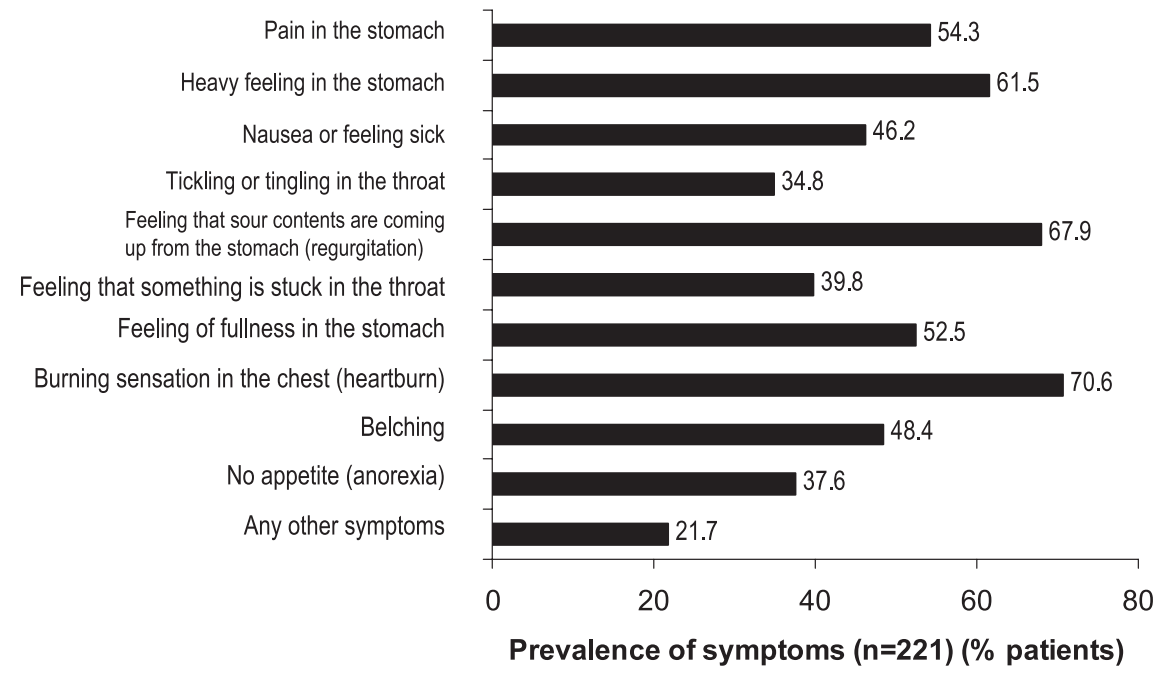

Fig. 1. Gastrointestinal symptoms reported by patients at baseline.

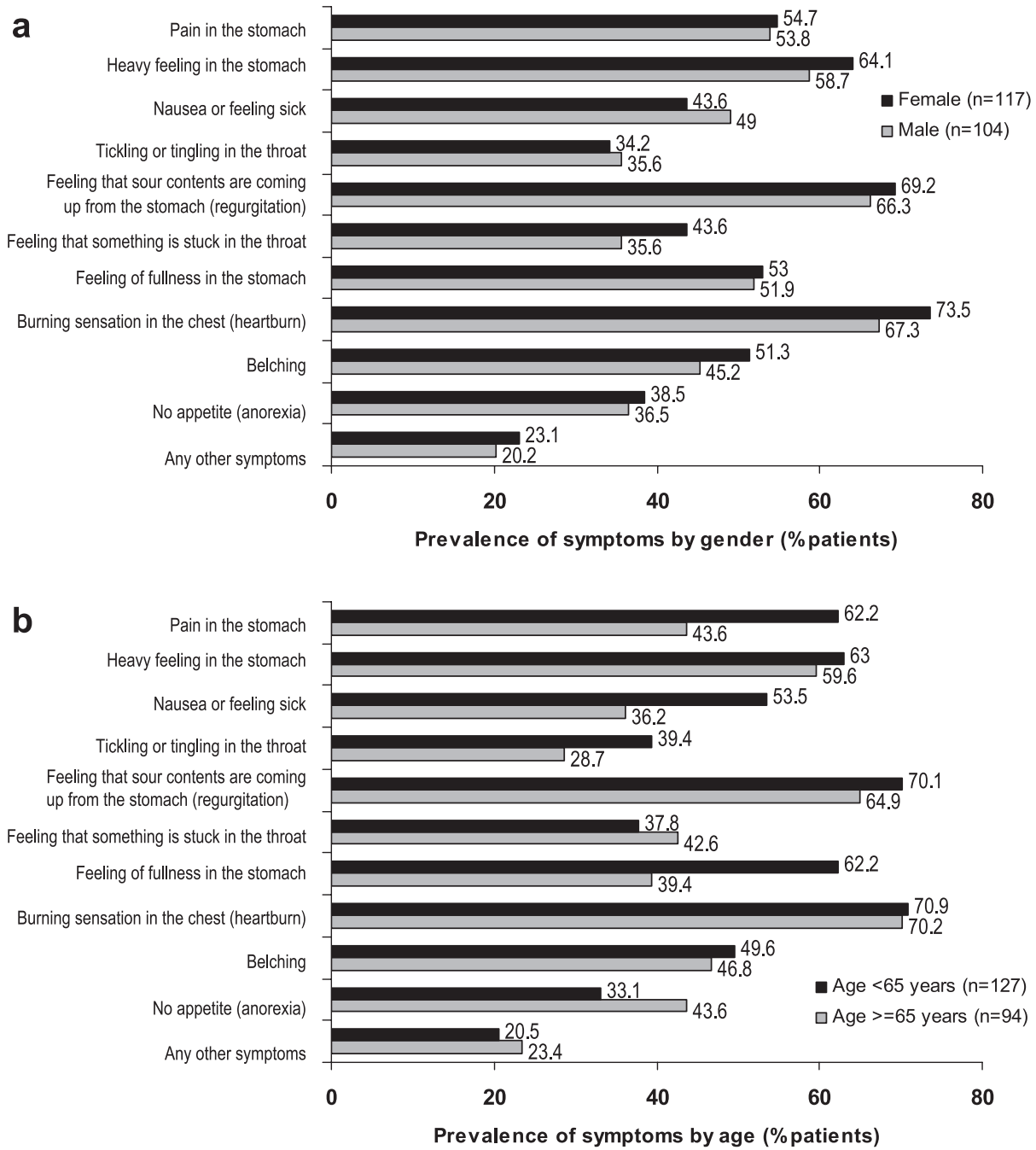

Fig. 2. Prevalence of gastrointestinal symptoms according to gender (a) and age (b). 
Symptoms presented at study entry are shown in Figure 1. The average number of symptoms was 5.4 per patient. The percentage of patients who reported 3 or more symptoms was $92 \%$ and who reported 6 or more was $39 \%$.

The most frequent symptoms were reflux-type, "Feeling that sour contents are coming up from the stomach (regurgitation)" and "Burning sensation in the chest (heartburn)", reported by approximately $70 \%$ of patients. While these symptoms were expected in patients with RE, a substantial percentage of ulcer- and dysmotility-type symptoms were also reported (Figure 1).

Symptom prevalence stratified by gender showed that "Heavy feeling in the stomach", "Feeling that something is stuck in the throat" and "Belching" complaints occurred often in females. Patients aged less than 65 years were more likely to experience "Pain in the stomach", "Nausea or feeling sick", "Tickling or tingling in the throat" or "Feeling of fullness in the stomach", while those 65 years or older had a high prevalence of "Feeling that something is stuck in the throat" (Figure 2).

\section{Symptom improvement rate}

The symptom improvement rate in patients with refluxtype symptoms and in those with ulcer- and dysmotility-type symptoms are shown in Figure 3. In those with reflux-type symptoms, improvement was achieved in $83-94 \%$ of patients at week 4. Almost the same improvement rates were seen at week 2, suggesting that omeprazole relieved symptoms early.

In patients with ulcer- and dysmotility-type symptoms, all symptoms except anorexia showed similar improvement to reflux-type: $71-86 \%$ of patients at week 2 and $84-94 \%$ at week 4 . Improvement rates for anorexia at weeks 2 and 4 were $61 \%$ and $71 \%$, respectively.

Symptom improvement rates at dosages of omeprazole $10 \mathrm{mg}$ and $20 \mathrm{mg}$ are shown in Table 4.
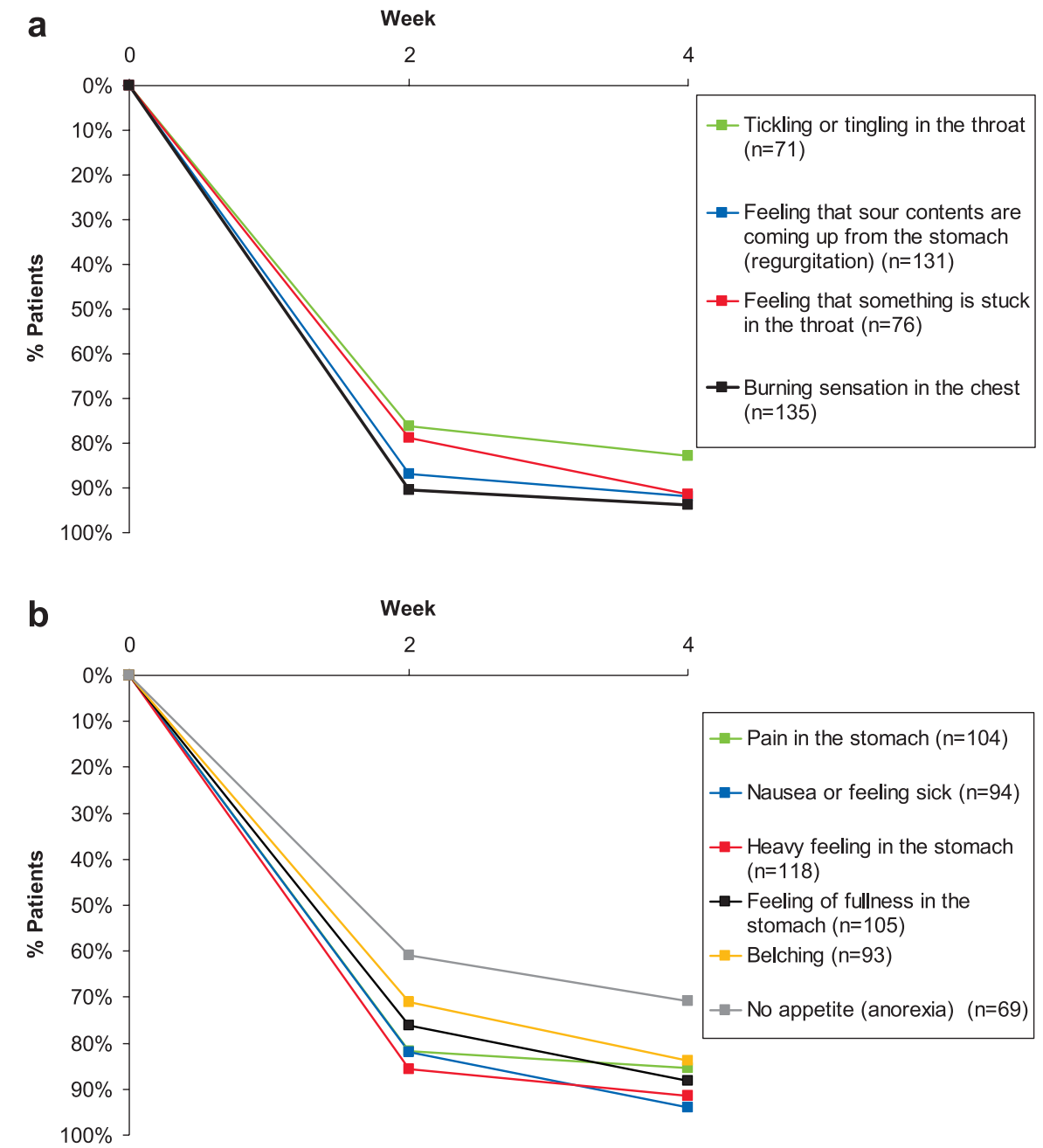

Fig. 3. Symptom improvement rate in patients with reflux-type symptoms (a) and ulcer- and dysmotility-like symptoms (b). 
Table 4. Symptom improvement rate in each dosage at week 4

\begin{tabular}{|c|c|c|}
\hline \multirow{2}{*}{ Symptoms } & \multicolumn{2}{|c|}{ Improvement rate } \\
\hline & $10 \mathrm{mg}$ daily & $20 \mathrm{mg}$ daily \\
\hline \multicolumn{3}{|l|}{ Reflux-type symptoms } \\
\hline $\begin{array}{l}\text { Tickling or tingling in the } \\
\text { throat }\end{array}$ & $93.3 \%(14 / 15)$ & $80.4 \%(37 / 46)$ \\
\hline $\begin{array}{l}\text { Feeling that sour contents } \\
\text { are coming up from the } \\
\text { stomach (regurgitation) }\end{array}$ & $85.7 \%(24 / 28)$ & $94.6 \%(88 / 93)$ \\
\hline $\begin{array}{l}\text { Feeling that something is } \\
\text { stuck in the throat }\end{array}$ & $86.7 \%(13 / 15)$ & $94.2 \%(49 / 52)$ \\
\hline $\begin{array}{l}\text { Burning sensation in the } \\
\text { chest (heartburn) }\end{array}$ & $92.3 \%(24 / 26)$ & $93.8 \%(90 / 96)$ \\
\hline \multicolumn{3}{|l|}{$\begin{array}{l}\text { Ulcer- and dysmotility-type } \\
\text { symptoms }\end{array}$} \\
\hline Pain in the stomach & $90.0 \%(18 / 20)$ & $83.6 \%(61 / 73)$ \\
\hline fasting & $80.0 \%(4 / 5)$ & $82.1 \%(23 / 28)$ \\
\hline after meal & $90.0 \%(9 / 10)$ & $90.0 \%(18 / 20)$ \\
\hline Nausea or feeling sick & $90.9 \%(10 / 11)$ & $95.7 \%(66 / 69)$ \\
\hline $\begin{array}{l}\text { Heavy feeling in the } \\
\text { stomach }\end{array}$ & $95.2 \%(20 / 21)$ & $89.9 \%(71 / 79)$ \\
\hline $\begin{array}{l}\text { Feeling of fullness in the } \\
\text { stomach }\end{array}$ & $80.0 \%(16 / 20)$ & $90.0 \%(63 / 70)$ \\
\hline Belching & $84.2 \%(16 / 19)$ & $83.3 \%(55 / 66)$ \\
\hline No appetite (anorexia) & $81.3 \%(13 / 16)$ & $67.4 \%(31 / 46)$ \\
\hline
\end{tabular}

\section{Complete symptom relief rate}

Reflux-type symptoms were completely relieved in 53$66 \%$ of patients at week 4 , while ulcer- and dysmotility-type symptoms were completely relieved in $48-63 \%$ of patients.

Complete symptom relief rates at dosages of omeprazole $10 \mathrm{mg}$ and $20 \mathrm{mg}$ are shown in Table 5. Complete symptom relief rates in ulcer- and dysmotility-type symptoms at week 4 after omeprazole $20 \mathrm{mg} /$ day dosing is slightly higher than the rates after omeprazole $10 \mathrm{mg} /$ day dosing, but a caution is necessary to interpret this result due to the smaller number of patients in $10 \mathrm{mg} /$ day dosing group. In reflux-type symptoms, the complete relief rates were $53-68 \%$ in both dosages.

\section{GSRS score}

A total of 164 out of 221 patients were comparable for GSRS score at study entry, week 2 and week 4. GSRS total score and five symptom categorical scores are shown in Figure 4. GSRS total score at entry was $2.2 \pm 0.7$ (mean $\pm \mathrm{SD}$ ) and was significantly improved to $1.6 \pm 0.6$ at week 2 and $1.5 \pm 0.5$ at week $4(\mathrm{p}<0.01)$. Reflux score, abdominal pain score and indigestion score were reduced by $1.0,0.7$ and 0.5 at week 2 respectively whereas smaller improvement was seen in diarrhea score $(0.2)$ and constipation score (0.3). All categorical scores were
Table 5. Symptom complete relief rate in each dosage at week 4

\begin{tabular}{|c|c|c|}
\hline \multirow{2}{*}{ Symptoms } & \multicolumn{2}{|c|}{ Complete relief rate } \\
\hline & $10 \mathrm{mg}$ daily & $20 \mathrm{mg}$ daily \\
\hline \multicolumn{3}{|l|}{ Reflux-type symptoms } \\
\hline $\begin{array}{l}\text { Tickling or tingling in } \\
\text { the throat }\end{array}$ & $53.3 \%(8 / 15)$ & $54.3 \%(25 / 46)$ \\
\hline $\begin{array}{l}\text { Feeling that sour } \\
\text { contents are coming } \\
\text { up from the stomach } \\
\text { (regurgitation) }\end{array}$ & $60.7 \%(17 / 28)$ & $62.4 \%(58 / 93)$ \\
\hline $\begin{array}{l}\text { Feeling that something } \\
\text { is stuck in the throat }\end{array}$ & $53.3 \%(8 / 15)$ & $63.5 \%(33 / 52)$ \\
\hline $\begin{array}{l}\text { Burning sensation in } \\
\text { the chest (heartburn) }\end{array}$ & $61.5 \%(16 / 26)$ & $67.7 \%(65 / 96)$ \\
\hline \multicolumn{3}{|l|}{$\begin{array}{l}\text { Ulcer- and dysmotility-type } \\
\text { symptoms }\end{array}$} \\
\hline Pain in the stomach & $35.0 \%(7 / 20)$ & $52.1 \%(38 / 73)$ \\
\hline fasting & $40.0 \%(2 / 5)$ & $42.9 \%(12 / 28)$ \\
\hline after meal & $50.0 \%(5 / 10)$ & $70.0 \%(14 / 20)$ \\
\hline Nausea or feeling sick & $36.4 \%(4 / 11)$ & $68.1 \%(47 / 69)$ \\
\hline $\begin{array}{l}\text { Heavy feeling in the } \\
\text { stomach }\end{array}$ & $38.1 \%(8 / 21)$ & $53.2 \%(42 / 79)$ \\
\hline $\begin{array}{l}\text { Feeling of fullness in } \\
\text { the stomach }\end{array}$ & $35.0 \%(7 / 20)$ & $55.7 \%(39 / 70)$ \\
\hline Belching & $42.1 \%(8 / 19)$ & $45.5 \%(30 / 66)$ \\
\hline No appetite (anorexia) & $56.3 \%(9 / 16)$ & $50.0 \%(23 / 46)$ \\
\hline
\end{tabular}

significantly improved after administration of omeprazole $(\mathrm{p}<0.01)$.

\section{Discussion}

A large number of patients complain of upper abdominal symptoms in daily clinical practice in Japan. Approximately $30 \%$ of the general population experience upper abdominal symptoms at least once a week according to the Gastroenterology Surveillance Study [11] in 10 countries, including Japan. While this result included symptoms from patients with organic disease such as PU and gastroesophageal reflux disease, the prevalence of FD in the general population has been reported in other studies: 11.5$14.5 \%$ in Western countries [12] and 13\% in Japan [13]. Hirakawa et al. suggested that the prevalence of non-ulcer dyspepsia, consisting of FD and reflux-like dyspepsia, was $17 \%$ among the Japanese population [14]. Thus, patients with upper abdominal symptoms are very common in Japan as well as in Western countries.

Patients with upper abdominal symptoms are commonly prescribed prokinetics in Japan, as acute gastritis or exacerbation of chronic gastritis is often the diagnosis, if organic disease is not found upon examination. Prokinetics 


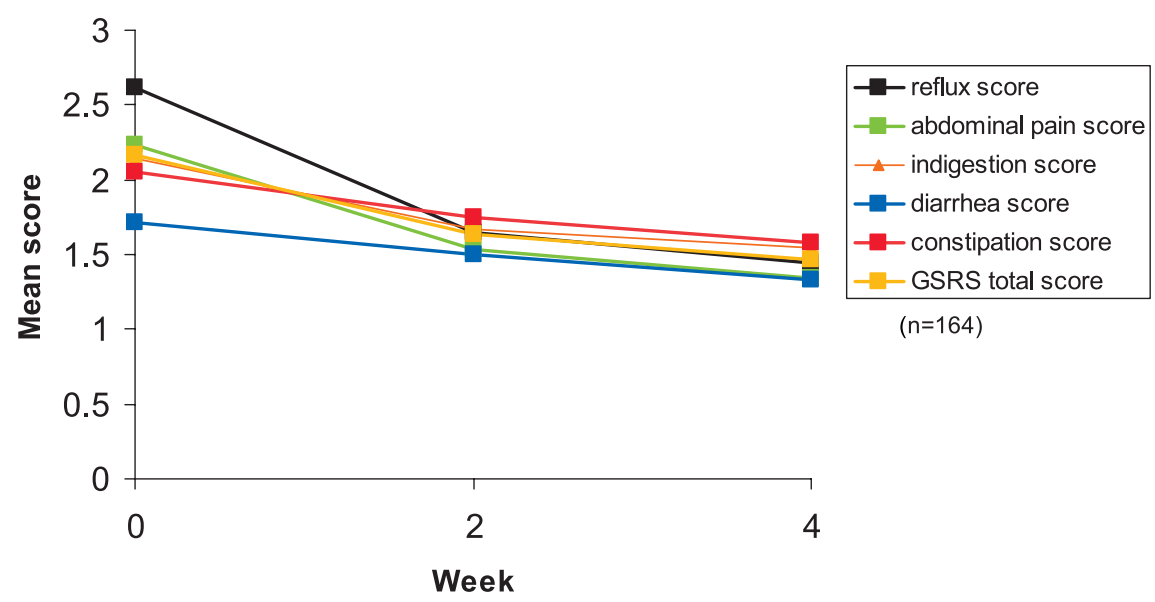

Fig. 4. Change in mean GSRS score over time.

are recommended for the treatment of dysmotility-like dyspepsia [15], but a satisfactory effect is not always achieved [3, 4]. In other words, those patients who visit hospitals have rather pronounced symptoms and decreased QOL, nevertheless, their symptoms are not well controlled by the medications given in most cases. This causes patients to change hospitals with their uncontrolled symptoms and anxiety [16].

Symptom control and improvement of QOL are the purpose of the treatment for patients suffering from upper abdominal symptoms. In Western countries, especially in primary care, an empiric trial of PPIs is recommended for the management of dyspepsia [17]. Omeprazole has been shown to be an efficacious treatment option in this case [18]. However, US recommendations may not be applicable for Japanese clinical practice due to the popularization of endoscopy and high prevalence of gastric cancer, yet the proposed link between upper abdominal symptoms and acid is interesting.

In the present study, reflux-type symptoms (e.g. burning sensation in the chest) and ulcer- and dysmotility-type symptoms (e.g. heavy feeling or pain in the stomach) were seen at study entry in patients with RE. Ulcer- and dysmotility-type symptoms were observed in up to $62 \%$ of patients, while reflux-type symptoms were seen in approximately $70 \%$. As presence of heartburn was not mandatory for patient selection in this study, it was estimated that approximately $30 \%$ of patients had a predominant symptom other than heartburn. Ulcer- and dysmotility-type symptoms are seen in a certain number of patients, and the mechanism of interaction with acid has been studied. As Lee et al. reported, increased gastric sensitivity to gastric distension due to duodenal acid exposure might cause the symptoms [19].

After omeprazole administration, almost all symptoms were improved by week 4 in approximately $90 \%$ of patients.
Similar improvement rates were achieved regardless of symptom types and dosage. The symptoms were completely resolved in $48-66 \%$ of patients. In a Canadian study in $H$. pylori-negative patients with dyspepsia, omeprazole showed superior symptom relief compared with ranitidine, cisapride and placebo [7]. Symptoms were improved or resolved by omeprazole treatment regardless of symptom types, suggesting that gastric acid is somewhat associated with upper abdominal symptoms and can be treated by PPIs.

QOL was measured by GSRS in this study. Reflux score was the worst at study entry and at week 4, all scores were improved significantly compared to the baseline score. Both diarrhea and constipation scores were significantly reduced, improvement from baseline score was minimum. QOL in patients with RE is lower than that in patients with heart failure (mild) and angina pectoris [20]. It is known that QOL in patients with FD is also decreased $[1,2]$ and may be as low as patients with RE due to upper abdominal symptoms. Once symptoms are relieved by PPI treatment, improvement of QOL in patients with upper abdominal symptoms is expected.

The purpose of this study was to collect symptom information observed in patients with RE and to investigate the efficacy of omeprazole on the symptoms. Ulcer- and dysmotility-type symptoms such as "Heavy feeling in the stomach" and "Feeling of fullness in the stomach" in addition to the typical symptoms of RE were frequently reported in patients entered in the study. Symptoms were improved or completely resolved after treatment of omeprazole and QOL was also improved. Although this was the study in patients with RE, this result may suggest omeprazole can be effective for the treatment of upper abdominal symptoms such as ulcer- and dysmotility-type symptoms as well as reflux symptoms regardless of gastrointestinal lesion. 


\section{Acknowledgments}

We thank Natalie Avenell-Mills, from Adis International Limited, who provided editing assistance.

We would like to also thank the following investigators, Shimane University School of Medicine; Furuta K., Amano Y., Ishihara S. Mitsubishi Mihara Hospital; Hamada H., Kido S., Yamauchi R. Saga Medical School; Amemori S., Fujise T., Ootani H., Sakata H., Sakata Y., Tsunada S. Kawasaki Medical School; Koga H., Sugiu K. Goubaru Clinic; Goubaru Y. Kawasaki Hospital; Fujimura Y. Kyoritsu Hospital; Tano N. Mitsubishi Mizushima Hospital; Miyashita K. Setonaikai Hospital; Kobori M. Shimane Adult Disease Prevention Center; Kaji T., Hirakawa K., Niigaki M. Suzuki Medical Gastrointestinal Clinic; Suzuki T. Takeo City Hospital; Kikkawa A., Sakata Y. Masuda Medical Association Hospital; Mishima I. Fuyuno Hospital; Fuyuno S. Izumo City General Medical Center; Yuki M. Kanzaki Clinic; Nakayama S. Karatsu City Hospital Kitahata; Fukuyama K. Kurashiki Medical Center; Okuyama T. Kyowa Marina Hospital; Nakamura Y. Meiwa Hospital; Kishi K. Mitsuoka Medical Gastrointestinal Clinic; Mitsuoka S. Nomura Kaihin Hospital; Toyoda T. Ochiai Hospital; Iguchi D. Ono Clinic; Ono T. Saga Social Insurance Hospital; Oyama T. Sugimoto Kenji Clinic; Sugimoto K. Tokumo Gastrointestinal Hospital; Tokumo K. Tottori Municipal Hospital; Aimi M., Fujishiro H., Maeshima R. Unnan Municipal General Hospital; Hamamoto N. Watanabe Clinic; Watanabe Y. Asahi Clinic; Kang K. Eguchi Hospital; Matsunobu A. Fujioka Hospital; Fujioka Y. Fujiyamato Onsen Hospital; Okada K. Hara Surgery Clinic; Hara H. Hyogo Prefectural Awaji Hospital; Kato T., Nishi K. JA Onomichi General Hospital; Sasaki A. Kaneda Hospital; Kawanishi M. Kishimoto Clinic; Kishimoto Y. Kuroda Clinic; Kuroda Y. Maeyama Medical Gastrointestinal Clinic; Maeyama H. Masuda Red Cross Hospital; Amano K. Matsue Seikyo General Hospital; Kawashima K. Mori Clinic; Mori H. Nishinomiya Kyoritsu Neurosurgical Hospital; Arai E. Saga Prefectural Hospital Koseikan; Nakahara S., Ogata S. Cardiovascular Center Sakakibara Hospital; Sakakibara T. Sasebo Kyosai Hospital; Arima S., Matsunaga K. Shinko Hospital; Yamada H. Tomonaga Clinic; Tomonaga M. Ueda Kinen Hospital; Nishina H. Watanabe Gastrointestinal Surgical Hospital; Watanabe T. Fujisaki Clinic; Fujisaki J. Izumi Gastrointestinal Clinic; Izumi A. Karatsu Red Cross Hospital; Noda T. Saiseikai Karatsu Hospital; Endo H. Kasai City Hospital; Kitajima N. Kobe Ekisaikai Hospital; Yamamura M. Koga Pediatric Medical Hospital; Ishibashi S. Matsunaga Medical Clinic; Matsunaga C. Miki City Hospital; Inoue H. National Hospital Organization Ureshino Medical Center; Tsuruta H. Yuaikai Oda Hospital; Sakata Y. Ono Municipal Hospital; Kawamura A. Otani Hospital; Otani K. Seiwa Hospital;
Yamaji S. Shimane Prefectural Central Hospital; Imaoka T., Miyaoka Y. Takarazuka Municipal Hospital; Sawada Y. Tanaka Medical Clinic; Tanaka T. Yamaguchi Hospital; Fujimura T. Yoneda Medical Clinic; Yoneda M. Terada Medical Clinic; Terada $\mathrm{H}$.

\section{References}

[1] Tougas, G., Chen, Y., Hwang, P., Liu, M.M., and Eggleston, A.: Prevalence and impact of upper gastrointestinal symptoms in the Canadian population: findings from the DIGEST study. Domestic/International Gastroenterology Surveillance Study. Am. J. Gastroenterol., 94, 2845-2854, 1999.

[2] Kusunoki, H., Haruma, K., Muranaka, A., Nagashima, Y., Koga, H., Kamata, T., Takeda, M., Honda, K., Fujimura, Y., Manabe, N., Kamino, D., Tanaka, N., and Chayama, K.: Functional Dyspepsia and Quality of Life. Therapeutic Research, 24, 403-406, 2003.

[3] Talley, N.J., Silverstein, M.D., Agreus, L., Nyren, O., Sonnenberg, A., and Holtmann, G.: AGA technical review: Evaluation of dyspepsia. American Gastroenterological Association. Gastroenterology, 114, 582-595, 1998.

[4] Thomson, A.B.R., Barkun, A.N., Armstrong, D., Chiba, N., White, R.J., Daniels, S., Escobedo, S., Chakraborty, B., Sinclair, P., and Van Zanten, S.J.: The prevalence of clinically significant endoscopic findings in primary care patients with uninvestigated dyspepsia: the Canadian Adult Dyspepsia Empiric Treatment - Prompt Endoscopy (CADET-PE) study. Aliment. Pharmacol. Ther, 17, 14811491, 2003.

[5] Talley N.J., Zinsmeister, A.R., Schleck, C.D., and Melton, L.J. 3rd.: Dyspepsia and dyspepsia subgroups: a populationbased study. Gastroenterology, 102, 1259-1268, 1992.

[6] Nakajima, S.: Epidemiology of Dyspepsia in Japan: A Review in Comparison with Western Countries. Clin. Gastroenterol., 18, 403-413, 2003.

[7] Veldhuyzen van Zanten, S.J., Chiba, N., Armstrong, D., Barkun, A., Thomson, A., Smyth, S., Escobedo, S., Lee, J., and Sinclair, P.: A randomized trial comparing omeprazole, ranitidine, cisapride, or placebo in helicobacter pylori negative, primary care patients with dyspepsia: the CADETHN Study. Am. J. Gastroenterol., 100, 1477-1488, 2005.

[8] Armstrong, D., Bennett, J.R., Blum, A.L., Dent, J., De Dombal, F.T., Galmiche, J.P., et al: : The endoscopic assessment of esophagitis: a progress report on observer agreement. Gastroenterology, 111, 85-92, 1996.

[9] Dimenäs, E., Glise, E., Hallebäck, B, Hernqvist, H., Svedlund, J., and Wiklund, I.: Well-being and gastrointestinal symptoms among patients referred to endoscopy owing to suspected duodenal ulcer. Scand. J. Gastroenterol., 30, 1046-1052, 1995.

[10] Hongo, M., Fukuhara, S., and Green, J.: QOL in digestive area-QOL assessment by GSRS Japanese edition-. Diagnosis and Treatment, 87, 731-736, 1999.

[11] Stanghellini, V.: Three-month prevalence rates of 
gastrointestinal symptoms and the influence of demographic factors: results from the Domestic/International Gastroenterology Surveillance Study (DIGEST). Scand. J. Gastroenterol. Suppl., 231, 20-28, 1999.

[12] El-Serag, H.B. and Talley, N.J.: Systemic review: the prevalence and clinical course of functional dyspepsia. Aliment. Pharmacol. Ther, 19, 643-654, 2004.

[13] Kawamura, A., Adachi, K., Takashima, T., Murao, M., Kutsube, T., Yuki, M., Watanabe, M., and Kinoshita, Y.: Prevalence of functional dyspepsia and its relationship with Helicobacter pylori infection in a Japanese population. $J$. Gastroenterol. Hepatol., 16, 384-388, 2001.

[14] Hirakawa, K., Adachi, K., Amano, K., Katsube, T., Ishihara, S., Fukuda, R., Yamashita, Y., Shiozawa, S., Watanabe, M., and Kinoshita, Y.: Prevalence of non-ulcer dyspepsia in the Japanese population. J. Gastroenterol. Hepatol., 14, 10831087, 1999.

[15] Harasawa, S.: NUD. J. Ther., 83, 917-920, 2001.
[16] Nozu, T.: What is Functional Gastrointestinal Disorders; FGID? Diagnosis and Treatment, 93, 348-353, 2005.

[17] Talley, N.J. and Vakil, N.: Practice Parameters Committee of the American College of Gastorenterology: Guidelines for the management of dyspepsia. Am. J. Gastroenterol., 100, 2324-2337, 2005.

[18] Meineche-Schmidt, V.: Empiric treatment with high and standard dose of omeprazole in general practice: two-week randomized placebo-controlled trial and 12-month follow-up of health-care consumption. Am. J. Gastroenterol., 99, 10501058, 2004.

[19] Lee, K.J., Vos, R., Janssen, J., and Tack, J.: Influence of duodenal acidification on the sensorimotor function of the proximal stomach in humans. Am. J. Physiol. Gastrointest. Liver Physiol., 286: G278-G284, 2004.

[20] Dimenäs, E.: Methodlogical Aspects of Evaluation of Quality of Life in Upper Gastrointestinal Diseases. Scand. J. Gastroenterol., 28 (Suppl. 199), 18-21, 1993. 